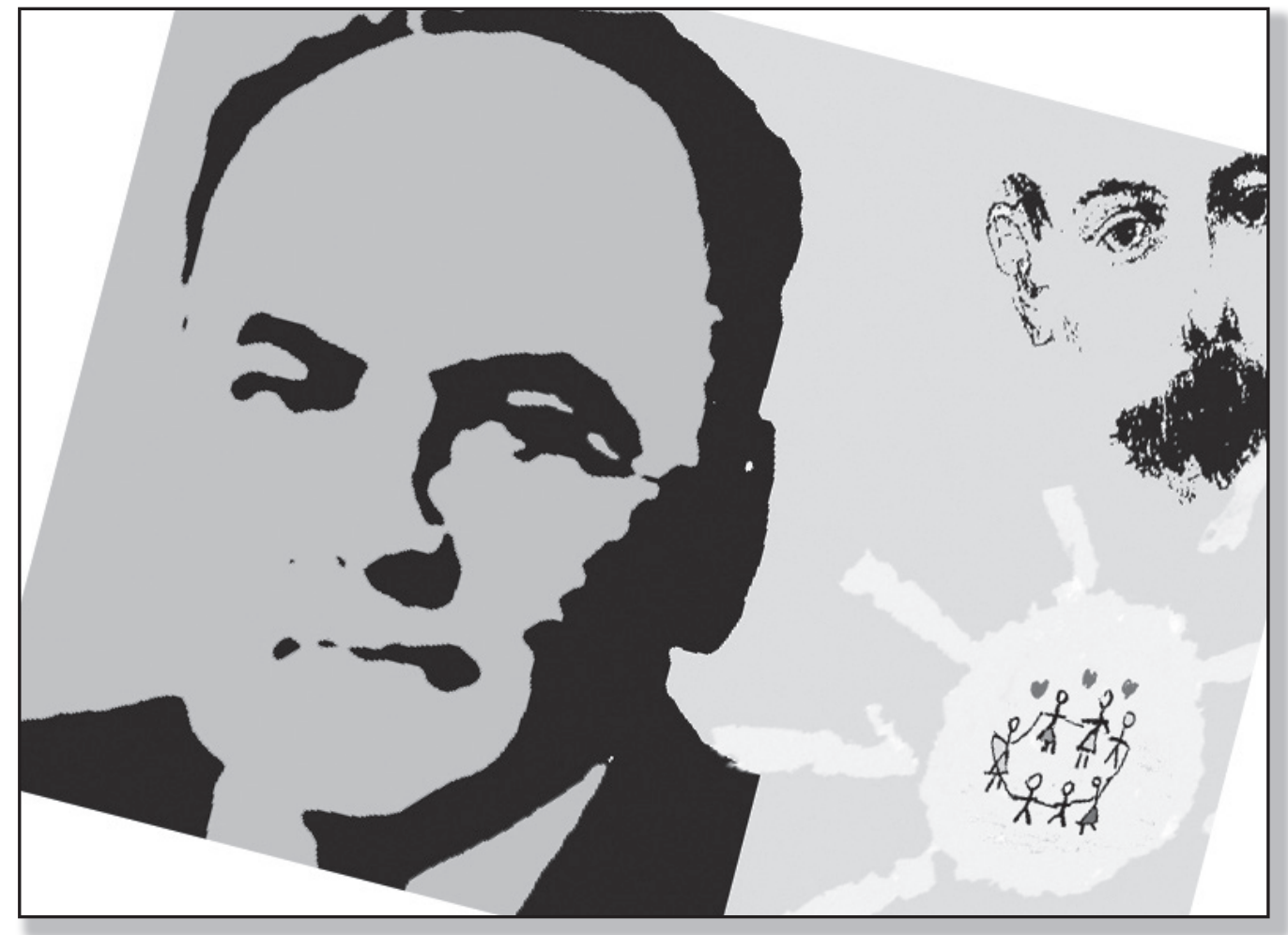

Fuente: original de Ronald Obando Brenes 


\title{
Experiencias didácticas mediante la literatura infantil latinoamericana
}

\section{Teaching Experiences through Latin American Children's Literature}

\author{
Nuria Rodríguez Vargas \\ Instituto de Estudios Latinoamericanos (IDELA) \\ Universidad Nacional, Costa Rica \\ nuria.rodriguez.vargas@una.cr
}

\begin{abstract}
Resumen
El presente trabajo tiene como objetivo presentar experiencias y aprendizajes en torno a la literatura infantil latinoamericana por medio de dos talleres dirigidos a docentes de I y II Ciclos de la Educación Básica del Sistema Educativo Público de Costa Rica, en los circuitos de la ciudad de Heredia durante el año 2017. Se trató de acercar al docente a la literatura infantil latinoamericana, mediante la lectura y análisis de diferentes obras narrativas. Las obras son representativas de diferentes períodos, contextos históricos, sociopolíticos y culturales de nuestro continente. De esta manera, se desarrolló la capacidad crítica, la identificación con valores regionales y el rescate de la memoria histórica latinoamericana a partir del mundo mostrado de las obras.
\end{abstract}

Palabras claves: talleres, literatura infantil, América Latina, memoria, derechos humanos, ideario martiano, La Edad de Oro 


\begin{abstract}
The goal of this study is to present experiences and lessons on Latin American children's literature by means of two workshops for teachers of I and II cycles of the general basic education of the public education system in Costa Rica, in the city of Heredia during 2017. The approach was to familiarize the teacher with the Latin American children's literature through reading and analysis of several narrative works. These works are representative of several periods, and socio-political and cultural contexts in our continent. Thus, we tried to develop an ability to criticize, as well as an identification with regional values and with the rescue of the Latin American historical memory from the world shown in the works.
\end{abstract}

Keywords: workshops, children's literatura, Latin American, historical memory, human rights, Martí's ideas, La Edad de Oro

\section{Introducción}

$\mathbf{E}$ ste trabajo pretende describir y recordar la experiencia pedagógica realizada con docentes del Sistema Educativo Público de Costa Rica y pertenecientes a los circuitos de Heredia. Los talleres se realizaron durante el año 2017 desde el Instituto de Estudios Latinoamericanos (IDELA) en colaboración con el Ministerio de Educación Pública (MEP).

Fiel a la misión del Instituto de Estudios Latinoamericanos (IDELA), la cual es: "Generar, articular y difundir conocimientos multi e interdisciplinarios sobre la región latinoamericana, y su contexto internacional", en 2017 inició el proyecto de investigación titulado: "El ideario martiano en los textos de La Edad de Oro editada como suplemento al Repertorio Americano y su proyección en la educación pública costarricense". Por tanto, los talleres se enmarcan dentro de este proyecto.
El Instituto de Estudios Latinoamericanos actualmente promueve el cultivo de una lógica de pensamiento histórico latinoamericano que profundiza en el conocimiento de la realidad de los pueblos latinoamericanos y propulsa transformaciones sociales significativas desde un sentido de aprendizaje crítico. Su labor incluye la generación, articulación y difusión de experiencias y conocimientos multi e interdisciplinarios y culturales desde América Latina; así como la promoción de los Derechos Humanos en los diversos contextos regionales. ${ }^{1}$

En el documento del Plan Estratégico 2013-2017 de la Facultad de Filosofía y Letras, en el objetivo estratégico de Facultad 1, se plantea:

Fortalecer la presencia de la Facultad en los ámbitos nacional e internacional,

1 Localizable en: http://www.idela.una.ac.cr/index.php/ sobre-el-idela/historia 
con el propósito de lograr una mayor incidencia y una mejora de la percepción social de nuestro quehacer.

Acción estratégica: acciones de cooperación con instituciones de educación superior y otros organismos nacionales y extranjeros con los que se comparten áreas de interés. Meta estratégica: Gestionar 30 acciones de cooperación con instituciones nacionales e internacionales mediante convenios, alianzas y otras acciones conjuntas Indicador: Cantidad de acciones de cooperación (nacionales, internacionales, tipo de organización, naturaleza de la cooperación).Responsable: Todas las unidades Plazo Desarrollo: 2013, 2014, 2015, 2017 (Plan Estratégico de Facultad 20132017, 2013).

De la misma manera, el mismo documento plantea como principales debilidades de la Facultad:

1. Vínculos de la Facultad hacia el ámbito nacional e internacional. Insuficientes alianzas para el desarrollo de nuevas iniciativas académicas, con instituciones de educación superior, así como con otros organismos nacionales e internacionales, que permitan mayor impacto del quehacer de la Facultad. 4. Divulgación: escasa divulgación de las actividades fuera del ámbito universitario, lo que genera poca participación en estas y bajo impacto.

En vista de lo anterior, el Instituto ha procurado desde sus proyectos de investigación y extensión llegar y llevar la universidad a la comunidad nacional. Así, el proyecto mencionado anteriormente tenía dos objetivos: por una parte, recuperar los seis tomos de
La Edad de Oro de Joaquín García Monge, quien emulando la del prócer cubano José Martí, compiló y editó su versión entre 1924 y 1930. Además, investigar sobre la influencia del pensamiento pedagógico de José Martí en la labor educativa de García Monge, en concreto en la obra mencionada. $\mathrm{Y}$, por otra parte, llevar a los docentes de primaria del sector público costarricense, el pensamiento martiano y garcía-mongeano mediante textos de literatura infantil y juvenil de "las edades de oro" de ambos autores y también de autores latinoamericanos de la época contemporánea.

La obra de García Monge tiene un valor intrínseco para el ámbito cultural costarricense; es un rescate de la producción literaria latinoamericana y universal, sistematizada como propuesta pedagógica y de la literatura infantil y juvenil (LIJ). La selección de textos trasciende las épocas, pues la buena literatura no tiene fecha de caducidad y siempre está vigente. De tal manera que se pudieron ligar los textos con las temáticas y los ejes transversales de los programas actuales del Ministerio de Educación Pública (MEP).

En 2017, se llevaron a cabo los talleres titulados "Memoria, cultura y derechos humanos en América Latina mediante la literatura infantil". Fueron dirigidos a docentes de primaria del sistema de Educación Pública, de las siguientes áreas: Educación Básica, Servicios de Educación Especial, Orientación, Educación Preescolar y Psicología.

Los talleres tenían como objetivo general acercar al docente de educación primaria del sector público costarricense a la historia 
de América Latina, bajo el eje transversal de los derechos humanos, mediante textos narrativos de literatura infantil, presentes en La Edad de Oro de Martí y la de Joaquín García Monge y también textos latinoamericanos de literatura infantil y juvenil contemporáneos. Los objetivos específicos de los talleres fueron los siguientes:

1. Reflexionar sobre la cultura e historia de América Latina.

2. Hacer memoria sobre los diferentes procesos históricos del continente.

3. Estudiar autores consolidados de la literatura infantil latinoamericana.

4. Leer obras infantiles latinoamericanas que dan cuenta de los procesos históricos y los derechos humanos.

5. Desarrollar un sentido crítico ante las creaciones dirigidas a los niños y niñas.

La modalidad de los talleres fue mixta: presencial y a distancia. La duración fue de 16 horas cada uno. El primero en los meses de marzo-abril, dirigido a 10 docentes de I y II ciclo de los circuitos de Heredia. El segundo, se impartió en los meses de julio y agosto, dirigido a 15 docentes del área de Orientación.

Los talleres siguieron una metodología participativa, es decir, se desarrolló una línea de trabajo en la que los participantes eran agentes activos en la construcción de conocimiento. La meta principal de la propuesta metodológica fue que todos los integrantes del grupo de docentes participaran, mediante actividades y técnicas participativas lúdicas, interactivas, creativas, desarrolladas en forma grupal para fomentar el diálogo, el intercambio de ideas, sentimientos, opiniones y la reflexión crítica. Se enfatizó en la discusión grupal, el intercambio de opiniones para descubrir que nuestra cultura está constituida por una pluralidad de elementos estéticos, económicos, históricos que muestran inclusiones y exclusiones en las construcciones identitarias y sociales nuestroamericanas. La estructura de los talles, en la parte presencial se compuso de los siguientes elementos:

1. Objetivos

2. Input

3. Contenidos

4. Actividades grupales

5. Materiales

6. Plenaria

Los objetivos de los talles están enmarcados dentro de un proyecto de investigación como se mencionó al principio. Cada sesión presencial y cada tarea virtual obedecen a los objetivos específicos del taller. En el input la persona facilitadora introducía algún elemento clave relacionado con la temática del día, mediante poemas, canciones, cortos audiovisuales o dinámicas, con el objetivo de generar diálogo.

Los contenidos fueron escogidos de acuerdo con los objetivos y el tiempo disponible. En este caso, fueron los diferentes textos de literatura infantil latinoamericana. Los talleres estuvieron enmarcados en los siguientes ejes temáticos: cultura latinoamericana, memoria y los derechos humanos. Por consiguiente, con respecto a la memoria y la desmemoria, se trabajó la censura en la literatura infantil latinoamericana en la época de las dictaduras, con respecto a los derechos de los niños y las niñas, temas que 
abordaron la igualdad de género, las familias diversas, derecho a una identidad, a no ser discriminado, entre otros.

Durante los talleres se proporcionaron materiales didácticos para el desarrollo de las actividades. Los textos literarios fueron sistematizados en una antología. Los textos de literatura infantil se trabajaron mediante actividades grupales, colaborativas y de construcción de conocimiento, en las que las personas docentes realizaron lecturas, análisis, elaboración de materiales, sociodrama, títeres, narraciones orales y exposiciones en forma conjunta.

Después de realizadas las actividades grupales, el cierre se hacía abriendo una plenaria. De tal manera que todo el grupo de reunía y escuchaba las exposiciones o demás actividades grupales. Se externaban opiniones y se reflexionaba sobre las temáticas tratadas en los mundos mostrados; la relación con las realidades e identidades latinoamericanas; la manera de aplicar los textos literarios en las realidades del salón de clase y el fomento de la lectura.

La parte virtual o a distancia se llevó a cabo a través del correo electrónico y consistía en el desarrollo de actividades individuales. Estas fueron evaluadas de mediante evaluación formativa, es decir, trabajo de orientación e interacción con los participantes y de forma sumativa utilizando rúbricas numéricas. Cabe destacar que la evaluación general de los talleres correspondió a la suma de las actividades presenciales y las virtuales.

\section{Aproximaciones conceptuales}

\section{Los derechos humanos}

Los derechos humanos son inherentes a todos los seres humanos, sin distinción alguna de nacionalidad, lugar de residencia, sexo, origen nacional o étnico, color, religión, lengua, o cualquier otra condición. Todos tenemos los mismos derechos humanos, sin discriminación alguna. Estos derechos son interrelacionados, interdependientes e indivisibles. ${ }^{2}$ Este constituye el ideal recogido en la Declaración Universal de los Derechos Humanos de 1948.

Se trató el tema de los derechos humanos desde el multiculturalismo que refiere a la coexistencia de culturas dentro de un mismo territorio, país o cultura sin pasar por discriminación de grupo étnico, cultura y sus implicaciones religiosas, lingüísticas, económicas y sociales. El objetivo es que respete la cultura de todos, especialmente de las minorías.

En este sentido se abordó el tema de los derechos humanos desde el multiculturalidad y la interculturalidad. El primer término implica la existencia de varias culturas que conviven en un mismo espacio físico, geográfico o social. Incluye todas las diferencias que existen dentro de la cultura: religión, lengua, raza, etnia o género. Se enfoca en el reconocimiento de la diversidad cultural en todos los ámbitos. Néstor García Canclini, citado por Carolina Mora, define el término de la siguiente manera:

2 Tomado de: http://www.ohchr.org/SP/Issues/Pages/ WhatareHumanRights.aspx 
La multiculturalidad es esa coexistencia de muchas culturas en un mismo espacio, nación o región. El multiculturalismo es una ideología que propicia la coexistencia, la aceptación de inmigrantes de diversos países, que busca organizarse con una política de coexistencia, la convivencia pacífica más o menos de todo (2016, en el prólogo, s/p).

Por otra parte, el término interculturalidad es la interrelación entre dos o más culturas de modo horizontal y cooperativo. Apunta Aleida Alavez Ruiz que es un término polisémico y tiene múltiples interpretaciones según el contexto en que se utilice, amplía al respecto:

La actual interculturalidad tiene que ver esa realidad con dos ojos; no solo etnia, no solo cultura, en el sentido de folclore, sino también como clase; y la interculturalidad crítica, además de intentar cambiar esos modelos que hasta hace poco se consideraban inmutables, únicos, también presenta de otra manera las culturas, no como entidades cerradas históricas que solo pueden aportarnos tradiciones históricas culturales, raíces, sino como sociedades, pueblos, culturas vivas que pueden aportar mucho, mucho más de lo folclórico a nuestras sociedades (2014, p.40).

Los términos suponen una valoración positiva de la diversidad humana, por lo tanto, se defiende la tolerancia, el respeto y la convivencia entre culturas diferentes e involucra las particularidades, características, hábitos, costumbres y tradiciones de cada cultura, sin que haya un sentido de superioridad de una cultura sobre las otras y que todas sean percibidas en el plano de la igualdad.
Los derechos humanos vistos desde los conceptos anteriores toman en cuenta a las minorías que se identifican por la diferencia religiosa, étnica, lingüística y cultural con respecto al Estado donde viven. En ocasiones, estas diferencias podrían conducir a sentimientos xenófobos. El concepto xenofobia es un vocablo proveniente del griego, compuesto por xénos "extranjero" y phóbos "miedo". Este miedo al extranjero podría traducirse en sentimientos de desconfiaza, rechazo y odio. Sin embargo, también se utiliza de forma más amplia para describir la fobia hacia grupos étnicos diferentes.

Desde la multiculturalidad y la interculturalidad el concepto minoría se amplía, destaca Carolina Mora Chinchilla que en América Latina en muchos casos, en el pasado se confundía el término minoría y se utilizaba para referirse a la población indígena y explica:

Se debe resaltar que estas poblaciones no son, en algunos de los países de América Latina una minoría, aunque se han "minorizado" igual que al grupo de mujeres. Esto lo logran al excluirlos de los mínimos básicos para la subsistencia digna, reducirles su capacidad de reproducir su cultura y privarlos de los beneficios que en general tiene la población llamada "blanca". Las minorías se reconocen fundamentalmente por su diferencia religiosa, étnica, lingüística y cultural en términos básicos (Mora, 2016, pp. 20-21).

Las experiencias se enmarcaron en el concepto de pedagogía intercultural la cual en la práctica educativa toma en cuenta las diferencias culturales de individuos y grupos 
para generar reflexión. Teresa Aguado define la pedagogía intercultural como:

La reflexión sobre la educación, entendida como elaboración cultural, y basada en la valoración de la diversidad cultural. Promueve prácticas educativas dirigidas a todos y cada uno de los miembros de la sociedad en su conjunto. Propone un modelo de análisis y de actuación que afecte a todas las dimensiones del proceso educativo. Se trata de lograr la igualdad de oportunidades (entendida como oportunidades de elección y de acceso a recursos sociales, económicos y educativos), la superación del racismo y la adquisición de competencia intercultural en todas las personas, sea cual sea su grupo de referencia (2003, p. 63).

De conformidad con lo anterior, tomando en consideración la población a la que fueron dirigidos los talleres, también se tomaron en cuenta algunos conceptos sistematizados por el Ministerio de Educación Pública (MEP) en torno a la educación intercultural en el contexto costarricense, la define de la siguiente manera:

Enfoque educativo basado en el respeto, valoración de la diversidad cultural, dirigido a todos y cada uno de los miembros de la sociedad, que propone un modo integrado y participativo de gestión educativa que busca fortalecer identidades locales y promover procesos pedagógicos de calidad, con pertinencia cultural y contextualizados. Es decir interculturales, para desarrollo de habilidades, conocimientos, actitudes y competencias necesarias para la formación de seres humanos integrales, solidarios, respetuosos de los derechos humanos, críticos y conocedores de las raíces culturales, abiertos al diálogo entre grupos culturales distintos a través de la interrelación entre lo propio, lo nuestro y lo de todos dentro de un marco de respeto, disfrute de la diversidad étnica, lingüística y cultural del país (Ministerio de Educación Pública, 2016, p. 9).

La Dirección de Desarrollo Curricular, Direcciones Regionales de Educación han tratado de orientar las asignaturas del Currículo Nacional hacia la Educación Intercultural, de tal manera que se han trabajado los siguientes ejes de acción: indigenismo, afrodescendencia, migración, refugiados, inclusión, riesgo social, derechos humanos, cultura, identidad y memoria histórica (Ministerio de Educación Pública, 2016, pp. 21-22).

\section{La cultura en América Latina}

El concepto de cultura es amplio y se puede abordar desde diferentes enfoques y disciplinas. El Departamento de Educación Intercultural del Ministerio de Educación Pública (MEP) maneja la siguiente definición acuñada por la Declaración Universal de la UNESCO sobre la Diversidad Cultural (2001), la cual define el término cultura como "conjunto de rasgos distintivos, espirituales y materiales, intelectuales y afectivos que caracterizan a una sociedad o a un grupo social y que abarca, además de las artes y las letras, los modos de vida, las maneras de vivir juntos, los sistemas, los valores, las tradiciones y las creencias" (Ministerio de Educación Pública, 2016, pp. 16-17).

Ya que se trabajaron experiencias pedagógicas desde la literatura infantil 
latinoamericana era preciso revisar cómo entienden o entendían el término algunos escritores de América Latina. El escritor colombiano Gabriel García Márquez, sobre la cultura latinoamericana:

En América Latina nosotros tenemos diversos elementos que pertenecen a muchas culturas que se han mezclado y esparcido por todo el continente. Es esto lo que da la riqueza y las posibilidades a la cultura en Latinoamérica. Por eso yo no creo que exista una cultura que se le pudiera llamar "colombiana" o "mexicana". Yo he dejado de sentir y de pensar como «colombiano», me siento un latinoamericano, y en ese sentido me siento orgulloso de ser latinoamericano (Poco café y mucha politica. Cuadernos para el diálogo, 1978).

En consonancia con lo anterior, el escritor mexicano Carlos Fuentes, en 1992, en el ensayo El espejo enterrado, propone que para ir al fondo del ser latinoamericano es necesario reconocerse en las tradiciones, indígena y africana, no solamente en la europea; aunque tampoco se debe negar; más bien, problematiza sobre los orígenes muy diversos de la península ibérica y su historia de invasiones, de conflictos y diversidad étnica y cultural, misma situación del enorme universo precolombino, plagado de lenguas, culturas y visiones de mundo muy diferentes.

De la misma forma la cultura africana trasplantada a América era diversa en orígenes, lenguas y culturas. Manuel Moreno Fraginals apunta al respecto: "Naturalmente, el comercio de esclavos africanos fue de tal magnitud que miles de ellos fueron más allá de estas actividades productivas y permearon todas las sociedades americanas". Y ligado al tema de la deculturación explica que es proceso consciente con objetivos de explotación económica y en el caso de los africanos en el Nuevo Mundo puede ser vista como un recurso de optimización del trabajo. Sin embargo, aclara que la deculturación total es imposible, "a los explotadores no les interesa hacer tabla rasa de los valores culturales de la clase explotada, sino solo de aquellos elementos que obstaculizan el sistema de explotación establecido" (1995, s/p). ${ }^{3}$

Por lo tanto, la africanidad en piel, alma y razón siempre ha permeado la sensibilidad, la cultura latinoamericana y sus manifestaciones. El siguiente poema del afroperuano Nicódemes Santa Cruz coincide con los planteamientos de Carlos Fuentes y refuerza la tesis de las bases culturales pues nuestra cultura es indo, afro, ibero americana.

\section{América Latina (1963)}

$$
\begin{aligned}
& \text { "¡Mi cuate!” } \\
& \text { "¡Mi socio!" } \\
& \text { “¡Mi hermano!” } \\
& \text { "AAparcero!" } \\
& \text { "¡Camarado!” } \\
& \text { "¡Compañero!" } \\
& \text { “Mi pata!" } \\
& \text { “¡M'hijito!” } \\
& \text { "Paisano...!" }
\end{aligned}
$$

He aquí mis vecinos.

He aquí mis hermanos.

3 Moreno, M. (1977). África en América Latina. Editorial Siglo XXI: México D.F, el texto original. 
Las mismas caras latinoamericanas

de cualquier punto de América Latina:

Indoblanquinegros

Blanquinegrindios

Y negrindoblancos

Rubias bembonas

Indios barbudos

Y negros lacios

Todos se quejan:

¡Ah, si en mi país

no hubiese tanta política...!

¡Ah, si en mi país

no hubiera gente paleolítica...!

¡Ah, si en mi país

no hubiese militarismo,

ni oligarquía

ni chauvinismo

ni burocracia

ni hipocresía

ni clerecía

ni antropofagia...

¡Ah, si en mi país...

Alguien pregunta de dónde soy

(Yo no respondo lo siguiente):

Nací cerca del Cuzco

admiro a Puebla

me inspira el ron de las Antillas

canto con voz argentina

creo en Santa Rosa de Lima

y en los orishás de Bahía.

Yo no coloreé mi Continente

ni pinté verde a Brasil

amarillo Perú

roja Bolivia.
Yo no tracé líneas territoriales

separando al hermano del hermano.

Poso la frente sobre Río Grande

me afirmo pétreo sobre el Cabo de Hornos hundo mi brazo izquierdo en el Pacífico

y sumerjo mi diestra en el Atlántico.

Por las costas de oriente y occidente doscientas millas entro a cada Océano sumerjo mano y mano

y así me aferro a nuestro Continente en un abrazo Latinoamericano.

De forma magistral y hermosa Santa Cruz apela a las diferencias culturales que existen en América Latina, desde el fenotipo, las características físicas, los colores diferentes y al mismo tiempo, mezclados; las variables dialectales de país y región; la inmensa y variada geografía; las diferentes formas de pensamiento, creencias religiosas, políticas y costumbres. Plantea las diferencias no como obstáculo, sino como fortaleza; el mestizaje y la hibridación cultural hacen grande y rica a la cultura latinoamericana, por lo que llama a la unión de todo el continente como estrategia para superar el pasado y enfrentar el presente y el futuro.

Además de la idea de la unión, es importante resaltar el concepto de pensamiento propio latinoamericano, a partir de las diferentes raíces culturales latinoamericanas, sus pensamientos y teorizaciones, ya lo había propuesto Gabriela Mistral en $E l$ grito (1922):

Maestro: enseña en tu clase el sueño de Bolívar, el vidente primero. Clávalo en el alma de tus discípulos con agudo garfio de convencimiento. Divulga 
la América, su Bello, su Sarmiento, su Lastarria, su Martí. No seas un ebrio de Europa, un embriagado de lo lejano, por lejano extraño, y además caduco, de hermosa caduquez fatal.

Artista: Muestra en tu obra la capacidad de finura, la capacidad de sutileza, de exquisitez y hondura a la par, que tenemos. Exprime a tu Lugones, a tu Valencia, a tu Darío y a tu Nervo: Cree en nuestra sensibilidad que puede vibrar como la otra, manar como la otra la gota cristalina y breve de la obra perfecta (1922). ${ }^{4}$

García Márquez, Fuentes, Santa Cruz y Mistral son herederos del pensamiento latinoamericanista de José Martí, quien veía en la heterogeneidad, la multiplicidad y la integración racial como una fortaleza nuestra, así lo expresó en el ensayo Nuestra América:

No hay odio de razas, porque no hay razas. Los pensadores canijos, los pensadores de lámparas, enhebran y recalientan las razas de librería, que el viajero justo y el observador cordial buscan en vano en la justicia de la naturaleza, donde resalta, en el amor victorioso y el apetito turbulento, la identidad universal del hombre. El alma emana, igual y eterna, de los cuerpos diversos en forma y en color. Peca contra la humanidad el que fomente y propague la oposición y el odio de las razas (1891, La Revista Ilustrada, Nueva York). ${ }^{5}$

Advertía Martí sobre los peligros de que los latinoamericanos no nos conozcamos:

4 Localizable en: http://www.bibliotecanacionaldigital. gob.cl/bnd/623/w3-article-137532.html

5 Localizable en: http://bibliotecavirtual.clacso.org.ar/ ar/libros/osal/osal27/14Marti.pdf falta de libertad y soberanía y dependencia económica y cultural, "ni se han de esconder los datos patentes del problema que puede resolverse, para la paz de los siglos, con el estudio oportuno y la unión tácita y urgente del alma continental". Así, en relación con el trabajo realizado una manera de conocerse, de reflexionarse y recordarse es mediante la exploración del pensamiento crítico latinoamericano y sus máximos representantes.

\section{Memoria}

De la palabra memoria en sus diferentes acepciones se podría decir lo siguiente: facultad psíquica por medio de la cual se retiene y recuerda el pasado, recuerdo que se hace o aviso que se da de algo pasado, exposición de hechos, datos o motivos referentes a determinado asunto. ${ }^{6}$ Sin embargo, se manejará un concepto que parte de lo individual para integrarse en lo social.

En la primera mitad del siglo XX Maurice Halbwachs analizó la relación entre memoria individual y memoria colectiva y entre esta última y la memoria histórica, es decir, se debería distinguir entre una memoria interior y una exterior del individuo, una personal y una social. Así, en la memoria colectiva se reorganiza el pasado por medio de recuerdos de la experiencia de una comunidad o grupo y la memoria histórica se abocaría a la reconstrucción de datos suministrados por el presente en la convivencia social, pero reflejados en un pasado recreado. Los tres tipos de memoria aludidos están enlazados por la experiencia.

6 Localizable en: https://dle.rae.es/memoria 
Maurice Halbwachs explicaba: "La vida de un niño está más sumida de lo que se cree en los medios sociales por lo que entra en contacto con un pasado más o menos lejano, que es como el marco en el que están prendidos sus recuerdos más personales. En ese pasado vivido, mucho más que en el pasado aprendido por la historia escrita, podrá apoyarse más tarde su memoria" (1968).

Halwachs fue marco referencial del término memoria: "Su definición sociológica de la noción de memoria colectiva explicado por ciertos fenómenos sociales, va adquiriendo un carácter práctico, el cual remite a ciertas formas del pasado (conscientes o inconscientes) compartidas por un colectivo o conjunto de individuos. Para este autor la memoria individual no es opuesta a la colectiva sino que se interpenetran" (Szurmuk y Mckee, 2013, pp. 175-176).

En las últimas décadas, el concepto memoria histórica se comenzó a entender como una definición divergente que pretende dar voz a las víctimas de procesos políticos opresivos o de los individuos que no están incluidos en las versiones oficiales o hegemónicas. "Hasta que los leones no tengan su propios historiadores, las crónicas de cacerías seguirán glorificando al cazador" decía Eduardo Galeano quien a través de sus relatos habló sobre los diferentes tipos de memoria: la memoria vaciada, olvidada, pesada, quemada; la memoria viva, porfiada o resurrecta; la memoria feliz, la memoria pintada, rabiosa, cruel y sumergida. Sobre la memoria mutilada reflexionó:

La memoria del poder no recuerda: bendice. Ella justifica la perpetuación del privilegio por derecho de herencia, otorga impunidad a los crímenes de los que mandan y proporciona coartadas a su discurso, que miente con admirable sinceridad. La memoria de pocos se impone como memoria de todos. Pero este reflector, que ilumina las cumbres, deja la base en la oscuridad. Los que no son ricos, ni blancos, ni machos, ni militares, rara vez actúan en la historia oficial de América Latina: más bien integran la escenografía, como los extras de Hollywood. Son los invisibles de siempre, que en vano buscan sus caras en este espejo obligatorio. Ellos no están. La memoria del poder sólo escucha las voces que repiten la aburrida letanía de su propia sacralización. "Los que no tienen voz" son los que más voz tienen, pero llevan siglos obligados al silencio, y a veces da la impresión de que se han acostumbrado. El elitismo, el racismo, el machismo y el militarismo, que nos impiden ser, también nos impiden recordar. Se enaniza la memoria colectiva, mutilada de lo mejor de sí, y se pone al servicio de las ceremonias de autoelogio de los mandones que en el mundo son. En: Le Monde Diplomatique, ed. española, julio-agosto de 1997).

En enlace con los conceptos anteriores, se escogieron y analizaron obras de la literatura infantil y juvenil latinoamericana para ser trabajados y analizados. "La literatura latinoamericana ha sido un campo muy prolífico en la descripción del pasado borrado u olvidado" (Szurmuk y Mckee, 2013, p. 176).

\section{Sobre literatura infantil}

La literatura siempre ha estado presente en la historia del ser humano, en las diversas culturas y civilizaciones, en forma oral 
y escrita. Cada pueblo o nación adquirió tintes o matices particulares, independientemente de la época, situación geográfica y cultural. Sin embargo, siempre han existido temas y problemas universales, la unidad de la literatura va más allá de las diferencias históricas y nacionales.

El nacimiento de toda literatura está ligado al folclor, la Real Academia de la Lengua Española lo define como: "el conjunto de creencias, costumbres, artesanías, tradiciones, canciones y bailes de un pueblo y sus interpretaciones." Las primeras manifestaciones de la literatura infantil se remontan a la palabra hablada y no escrita. Cada pueblo o cultura tiene narraciones maravillosas protagonizadas por seres heroicos o divinos, situadas en un tiempo histórico; y que sirven para explicar o interpretar el origen del mundo o realidades humanas de significación universal, estas narraciones son los mitos.

Es hasta el siglo XIX que las imprentas de América Latina tienen como destinatarios a los niños. Sin embargo, las primeras ediciones estaban destinadas al aprendizaje de la lectura y catecismos. En este contexto es que el escritor cubano José Martí quien con la publicación de la revista La Edad de Oro, intentó educar a la niñez latinoamericana en el amor por sus propias raíces americanas y el reconocimiento de nuestra cultura mestiza; de una manera lúdica a través del ingenio, la metáfora y la narración.

En los primeros años del siglo XX todavía se encontraba el género sometido a los intereses de la escuela. No obstante, en todos los países latinoamericanos existía una preocupación por la literatura para niños, tanto de escritores que escribían especialmente para niños como, Rafael Pombo, como otros ya consolidados en la literatura para adultos, por ejemplo: Rubén Darío, Horacio Quiroga, Amado Nervo y Juana de Ibarbourou. Obras de todos ellos fueron incluidas en La Edad de Oro sistematizada y editada por Joaquín García Monge.

En relación con otros países latinoamericanos la literatura costarricense tuvo un desarrollo relativamente tardío, debido a las diferencias políticas y económicas con respecto a otras naciones. En medio de una serie de transformaciones económicas, ideológicas y culturales y con el auge del periodismo a finales del siglo XIX, comienza a evolucionar nuestra literatura. Se utiliza el periódico el primer medio de difusión de cuentos cortos, relatos y cuadros de costumbres. En el caso específico de la literatura infantil, su arranque está marcado por la fundación de la Escuela Normal en 1914 y por el impulso de Joaquín García Monge en la revista Repertorio Americano.

¿Qué es literatura infantil y cuáles son sus funciones? No es una pregunta simple de contestar pues hay múltiples definiciones al respecto. La producción de una literatura dirigida a la población infantil obedece a criterios de un cambio de perspectiva con respecto al niño como un sujeto social. La historia de la evolución de un pueblo se logra con los cambios económico, sociales, morales, pero también se logra estudiando el trato que se le ha dado al niño como sujeto de análisis y cuidado (López, 1990, p.9). 
Fue en la segunda mitad del siglo XX que se comenzó a teorizar y estudiar a profundidad aspectos relacionados con la literatura dirigida a la población infantil. En la revista Repertorio Americano apareció un texto del escritor costarricense Fabián Dobles en el que hace una hermosa y poética reflexión sobre el tema, a continuación reproduzco partes del valioso texto:

Así como la vida del niño y su cauce están en el juego, la literatura infantil es tremendamente juguetona. Es la jocundidad hecha poesía, cuento y metáfora. Todo es posible en ella, como lo es en el juego, porque está regida por la lógica de lo maravilloso, en que el razonamiento no existe como tal, pue se tiñe todo de la voluntad de jugar, del querer colorearlo de maravilla y sueños. Es, por cierto, sueño puro la verdadera literatura infantil (...) Sucede fuera del tiempo que marcan los relojes y fuera del espacio cotidiano, y la habilidad del maestro que adapta o aplica en su escuela una dramatización, una poesía, un trozo cualquiera, está en encontrar el modo de atar lo irreal a lo real, siempre a través de ese sueño y es prodigio paralógico de lo infantil, mas sabiendo hacerlo siempre en el grado de equilibrio que cada edad le indique. Porque el niño no va al cuento ni a la poesía para aprender nada. Qué sabe él de ética o estética. Va por la necesidad psíquica de aprehender or aprehendiendo por el milagro de lo maravilloso. Va por jugar al sueño: a la hormiguita que habla y llora, al abejoncito que da lecciones vestido de frac, o al duende que, precisamente por no existir, es su misma existencia (...) por eso, la labor de la escuela no debe limitarse a enseñar a los niños la gramática y la aritmética corrientes, sino la gramática de la belleza y la aritmética de la emoción. Porque el alma existe, sí, pero hiperbólicamente podría decirse que no la llevan todos los hombres. Los hay que la tienen grande, y los hay que no la cargan del todo porque, de niños, nadie se cuidó de descubrírsela (...) (Repertorio Americano, 10 de diciembre de 1948).

En el fragmento anterior, Dobles toca varios punto importantes alrededor de la literatura infantil, primeramente lo lúdico y ligado a este concepto el poder de la metáfora, la fantasía y la belleza. Por otra parte, la función y responsabilidad que tienen el maestro y la escuela en la promoción de la lectura y la literatura infantil en la formación de un ser humano integral y sensible. Tocar y descubrir el alma a través de la magia, de la ficción, "es a través de esta alma, en este mundo mágico, que buscamos la unión con lo viviente, con lo existente, con lo cósmico" (Ferreto, 1985, p. 7).

Los conceptos de magia y belleza en la literatura infantil no están supeditados a la presencia de personajes bellos, buenos y armoniosos; pasa también por las emociones que provocan los personajes misteriosos, oscuros y "malos", ya que acercan al lector a una concepción eminentemente humana, "antes de hablar y de pensar, nuestros antiguos padres conocieron el bienestar y la desazón, la ternura, el amor, el odio, la alegría y el terror" (Ferrero, 1985, p.8).

Lo expuesto anteriormente no significa que la literatura infantil debe abandonar su función social, la reflexión y la transmisión de valores, claro, sin caer en textos simples, moralizantes y panfletarios, esta ha sido y es todavía una gran discusión 
teórica. La escritora argentina Graciela Montes ha reflexionado sobre la dicotomía fantasía/realidad, ya que existe una batalla entre los defensores de la realidad y los defensores de la fantasía, la cual ha tenido mucha relevancia en el sector de la pedagogía, como apunta Daniel Goldin (prefacio, 1999, p. 7).

La palabra "frontera" remite a una línea imaginaria que separa a un estado de otro, los humanos deciden políticamente, por medio de acuerdos en dónde termina y si a ese vocablo lo acompañamos del adjetivo "indómita": difícil de domar, de someter, de controlar. Entonces, los dos juntos, "la frontera indómita", aluden a una bella metáfora que describe la complejidad de la literatura infantil y dos de sus componentes: la realidad y la fantasía. "La literatura, como el arte en general, como la cultura, como toda marca humana, está instalada en esa frontera. Una frontera espesa, que contiene de todo, e independiente: que no pertenece al adentro, a las puras subjetividades, ni al afuera, el real o mundo objetivo" (Montes, 1999, p.52).

En ese sentido, Montes apunta a dos fantasmas, el tradicional de la escolarización y el fantasma de la frivolidad. El primero, pasa por posiciones políticas y religiosas, busca la utilidad de demandas externas y muchas veces recurre a la censura. El segundo, es light y llevó la antes saludable expresión "el placer de leer" a niveles de facilidad y comodidad. Sin embargo, sobre estos dos seres sitúa al tercer fantasma, más poderoso que los anteriores, el mercado y su ley de rédito máximo: lo que vende manda (Montes, 1999, pp. 56-58). Finaliza su crítica:
Está claro que el momento no es el propicio, que las circunstancias nos son adversas. Sin embargo, o por eso precisamente, yo hablo aquí de ensanchar la frontera, de construir imaginarios, de fundar ciudades libres, de hacer cultura, de recuperar el sentido, de no dejarse domesticar, de volver a aprender a hacer gestos, a dejar marcas. Ilusa, creo que todavía vale la pena aprovechar que al lobo se le ha hecho tarde para jugar un buen juego, dejarse entibiar por un rayo de sol antes de que llegue la noche y el silencio (Montes, 1999, p.59).

En la misma línea la investigadora Teresa Colomer se refiere a las funciones de la literatura infantil y juvenil. Sostiene que predominan algunas ideas, por ejemplo que los libros deben servir para enseñar a los niños modelos de buen comportamiento, o como material para trabajar temas diversos del currículo, o por otro lado, para ofrecer experiencia artística a los pequeños. La autora llama a la reflexión y a no posicionarse en uno u otro lado de la frontera, su posición es que la literatura para niños y jóvenes debe ser y verse como literatura y esquemáticamente resume las funciones de estos textos en tres puntos: acceso al imaginario de una sociedad determinada, desarrollo del dominio del lenguaje y la representación del mundo como instrumento de socialización de las nuevas generaciones (2010, p. 15).

Finalizo esta breve revisión con una disertación de la escritora argentina María Teresa Andruetto, sobre la literatura y que sintetiza muy bien lo que se ha venido diciendo en las páginas anteriores, apunta: 
La literatura no es solo un conjunto de palaras colocadas en armonía sobre la página, también es pensamiento; utiliza para ser la más compleja construcción social, que es el lenguaje; e intenta, cavando en esa tierra de todos, edificar una lengua privada. Por esta razón, como todas las artes, pero todavía más, la literatura es al mismo tiempo íntima y social; lo es en sus ideas, pero más aún en el modo en que utiliza el lenguaje, que es un bien de todos, y en la manera en que eso que es de todos se refleja en la subjetividad individual. Así, el cosmos de significación personal que construimos al escribir y recreamos al leer, se dirige doblemente a la sociedad de donde proviene, porque se construye con un bien social y se alimenta de los relatos que esa sociedad genera, por todo lo cual nos incluye doblemente (2014, p. 117).
En síntesis, la anterior exposición tocó aspectos relacionados con la definición de la literatura infantil y juvenil, sus funciones y su presencia en la escuela. Dentro de las funciones de la literatura se encuentran las siguientes: estética, social, cultural, musical, afectiva, simbólica y de compromiso, estas no deberían disputarse un predominio sino que juntas pueden articularse para analizar, reflexionar y disfrutar un texto literario. En un contexto histórico dominado por el fantasma del mercado como señala Graciela Montes, existe una responsabilidad del docente en la escogencia y aproximación a los textos literarios y la mediación pedagógica con los estudiantes. Y, por otra parte, la tentación de utilizar la literatura solamente como instrumento o material pedagógico para desarrollar temáticas del currículo, el reto está en lograr un equilibrio entre utilidad, reflexión y goce.

Tabla. 1. Desarrollo de LIJ latinoamericana

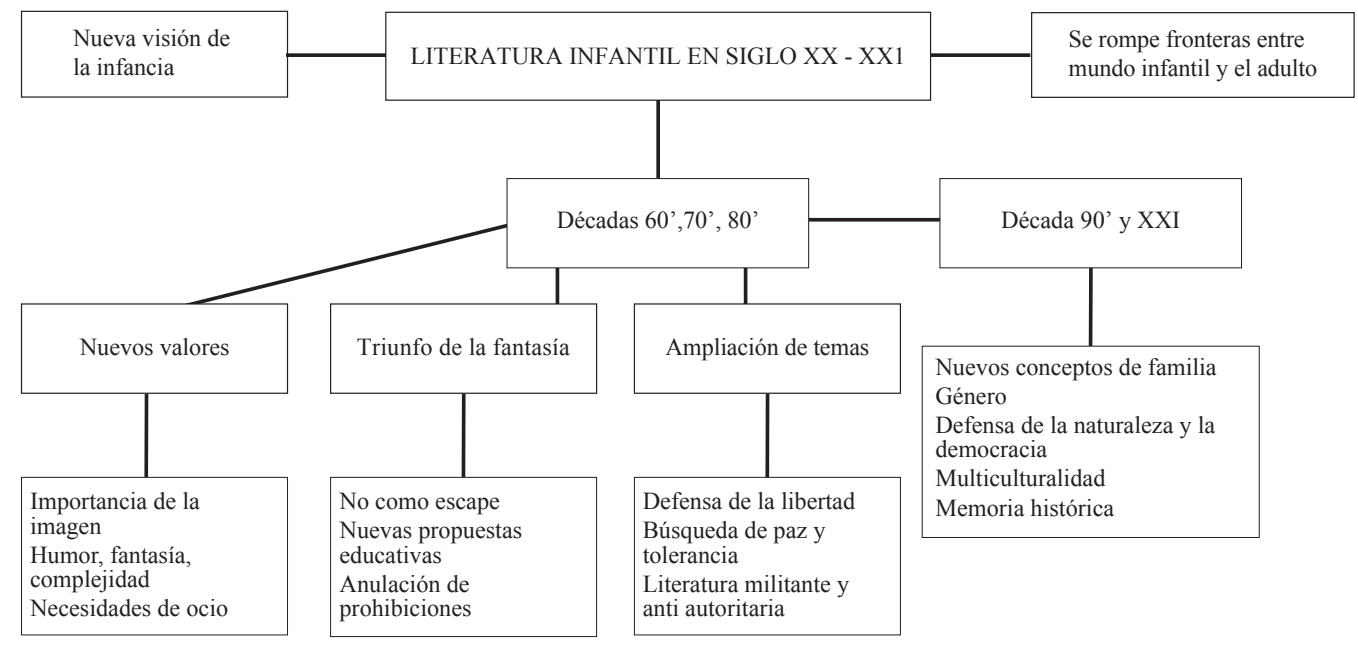

Fuente: Elaboración propia 


\section{Los textos literarios}

La selección de los textos literarios respondió a los objetivos del proyecto en el que estaban enmarcados los talleres. Se parte de textos publicados por José Martí en La Edad de Oro (1889) para extender un puente hasta la segunda mitad del siglo XX y primeras décadas del siglo XXI. Se seleccionaron los textos tomando en cuenta las siguientes razones: la calidad artística de los mismos desde el fondo y la forma, la pertenencia a autores del canon literario latinoamericano, temas y motivos relacionados con los derechos humanos y la memoria histórica.

Reunidos en el libro Puentes de palabras (2018) editado por Sergio Andricaín y Pedro C. Cerillo varias personas escritoras latinoamericanas, dan su opinión sobre lo que puede aportar a los niños y jóvenes la lectura de obras literarias, ellos son: Manuel Peña Muñoz, Martha Riva Palacio, Lucrecia Maldonado y Nilma Lacerda respectivamente, quienes reflexionan: "el desarrollo de la imaginación y la creatividad, el cultivo del mundo interior y la afectividad (...) abre puertas a la mente para interesarse por otras vidas humanas y otros espacios (p. 103), "el vértigo y el gozo de transformarse, aunque sea por un instante (...) ampliar nuestro horizonte" (p.111), "tomar contacto con luces y sombras de la naturaleza humana, sobrepasando la moraleja simple y el sentimentalismo fácil" (p.79), "la conciencia de que es humano, y esto implica dudas, imprevistos, errores y una responsabilidad de su condición frente a todo lo que vive" ( p.75). Hay coincidencia en que los textos literarios deben ser hermosos, pero no vaciados de contenido, provocar la reflexión personal y la empatía social.

Se escogieron tres obras que pertenecen o están enmarcadas en la llamada literatura de las dictaduras, son las siguientes: $U n$ elefante ocupa mucho espacio (1975) de la argentina, Elsa Bornemann, El pueblo que no quería ser gris (1975) de la también escritora argentina, Beatriz Doumerc y La composición (1979) del chileno Antonio Skármeta.

La censura tiene que ver con lo que no se ajusta a específicos planteamientos políticos, morales o religiosos. En este caso, interesa la censura ejercida sobre los libros, la cual ha acompañado al ser humano a lo largo de los siglos: quemas de libros, de bibliotecas enteras y persecución de autores. El historiador y escritor francés Lucien X. Polastron en el libro, Libros en llamas. Historia de la interminable destrucción de las bibliotecas (2007) hace un recorrido por todas las geografias y épocas: la era del papiro durante el desarrollo de Egipto, Grecia, Roma y Constantinopla; los reinos asiáticos del bambú, la meditación y el pincel: China, India y Japón; la gente del libro: el pueblo judío, el islam, tanto en medio oriente y África como en Europa; el occidente cristiano, de la Edad Media a la era moderna, pasando por la Inquisición; en el siglo XX, la Alemania nazi, la Rusia estalinista, los convulsos Balcanes, hasta el desmantelamiento contemporáneo de las bibliotecas.

En el libro Historia de la lectura (1998), Alberto Manguel define la censura de la siguiente manera: 
La censura, en una forma u otra, es el corolario de todo poder, y la historia de la lectura se ilumina con una hilera, en apariencia interminable, de hogueras encendidas por los censores, desde los rollos de papiros más antiguos hasta los libros de nuestro tiempo (p. 316).

Durante la dictadura argentina (19761983), explican Bialet y Luján, sucedió algo nuevo la represión cultural puso sus ojos en la literatura infantil ya que por la poca edad de los niños los niños se podrían convertir en instrumento de formación ideológica. Y continúan:

La represión cultural argentina tuvo algunas peculiaridades que la distinguen de otras censuras. En primer lugar, no existía la censura previa para la literatura (sí para el cine y la televisión). Se podía publicar lo que se quisiera, pero el editor corría el riesgo de perder la edición. De hecho algunas editoriales fueron cerradas y otras vieron cómo ardía gran parte de sus fondos. Esto fomentó la autocensura y el temor a publicar (2016, 279-280).

De tal manera que los libros argentinos anteriormente listados estuvieron en la lista de los prohibidos. Un clásico de la literatura infantil argentina, El pueblo que no quería ser gris de Beatriz Doumerc e ilustrado por Ayax Barnes fue publicado en 1975 por Rompan Fila Ediciones, prohibido en 1976 por el decreto $n^{\circ} 1888$, la notificación enviada a la editorial decía lo siguiente:

De mi mayor consideración: me dirijo a usted a efectos de poner en su conocimiento que, por Resolución $\mathrm{N}^{\circ} 437 / 76$ $\mathrm{SC}$, prohibióse la circulación por los servicios postales de la Empresa, de las publicaciones tituladas "La Ultrabomba" y "El pueblo que no quería ser gris", editadas en la Capital Federal de conformidad con los prescripto en el artículo $1^{\circ}$ del Decreto del Poder Ejecutivo Nacional $N^{\circ} 1888 / 76$. Saluda a usted atentamente. Aldo Colli, Jefe de la Sección Promoción del Departamento de Correos (En: Plan Nacional de Lectura, http://planlectura.educ.ar/?p=897).

La misma suerte corrió Un elefante ocupa mucho espacio de Elsa Bornemann fue prohibido por decreto, en octubre de 1977. "Es una compilación de 15 relatos que incluye un rey tirano desalojado a fuerza de pintura verde, chicos que se rebelan contra leyes antojadizas y al elefante del título que un día se le ocurre declararse en huelga. Tanta libertad le olió mal a la Junta Militar encabezada por Videla y finalmente prohibió el libro" (Guevara y Molfino, 2005, p. 9).

Al otro lado de la cordillera, en Chile durante la dictadura hubo censura de manifestaciones artísticas en general. "La LIJ no fue ajena a la censura durante el régimen de Pinochet, pero al contrario de lo que ocurrió con la censura de la literatura en general, la censura de la LIJ fue más bien, soterrada, solapada. No se han encontrado listas explícitas de autores u obras prohibidas, solo recomendaciones de lecturas y muchas omisiones" (Llorens y Díaz, 2016, p.334).

La obra, La Composición del escritor chileno Antonio Skármeta fue publicada inicialmente en 1979 en el periódico francés Le Monde, en los años posteriores a la dictadura se ha reeditado en formato de libroálbum. Es la historia de Pedro, un niño que 
vive con sus padres en la época de la dictadura chilena y remite al concepto de la memoria histórica, el nunca olvidar.

Por otra parte, dentro de las obras incluidas, hay textos que se relacionan con los derechos de la infancia: amor, igualdad, identidad, educación, protección, integración, solidaridad, calidad de vida, auxilio y denuncia. El texto poético del uruguayo Rubén Rada, recuerda muy bien, de qué se tratan estos derechos:

\section{Yo quiero $^{7}$}

Yo quiero que a mí me quieran, yo quiero tener un nombre yo quiero que a mí me cuiden si me enfermo o estoy triste porque yo quiero crecer.

Yo quiero saberlo todo yo quiero que a mí me enseñen mi familia y mi maestra a contar y a hacer las letras $\mathrm{y}$ me quiero divertir.

A jugar, a cantar, que me enseñen a ser libre y me digan la verdad. A jugar, a cantar, que me escuchen cuando hablo y que no me hagan llorar.

Pero quiero que también todos los niños del mundo tengan todo lo que quiero pues lo quiero compartir.

A jugar, a cantar que tengan todos los niños en el mundo su lugar.

Vamos todos a cantar pa' que los niños del mundo tengan todos un lugar.

7 Localizable en: https://www.musica.com/letras. asp?letra $=1825346$

\section{Descripción de las actividades realizadas en el taller}

\section{Actividades presenciales}

\section{Actividad 1}

\section{Temas}

Definición de América Latina

La memoria y la desmemoria

La literatura infantil y la censura de las dictaduras

\section{Textos literarios}

1. El Desmemoriado

2. Un elefante ocupa mucho espacio

3. El pueblo que no quería ser gris

4. La Composición

\section{Actividades}

1. Introducción a través de dinámicas y vídeos

2. Lectura de cuentos

3. Actividad grupal: narración oral de un cuento

\section{Materiales}

- Marcadores

- Lápices y crayolas de colores

- Papel construcción de colores

- Pegamento

- Masking tape

- Papelógrafos

- Hojas adicionales

- Copias de documentos

- Lapiceros

\section{Actividad 2}

\section{Temas}

Derechos de los niños y las niñas. Igualdad de género. Igualdad de origen, cultura, etc. 


\section{Cuadro 2. Obras y autores leídos y analizados en el taller}

\begin{tabular}{|c|c|}
\hline Obra/Autor/a & Temas \\
\hline 1. La muñeca negra (1889). José Martí. Cuba & La integración social \\
\hline 2. Bebé traviesa (1889). José Martí. Cuba & Las familias monoparentales \\
\hline 3. Los zapatitos rojos (1889). José Martí. Cuba & La solidaridad \\
\hline 4. Un elefante ocupa mucho espacio (1975).Elsa Bornemann. Argentina & Las dictaduras \\
\hline 5. El pueblo que no quería ser gris (1975). Beatriz Doumerc. Argentina & Las dictaduras \\
\hline 6. La composición (1979). Antonio Skármeta. Chile. & Las dictaduras \\
\hline 7. Niña Bonita (1986). Ana María Machado. Brasil & Las familias multiculturales \\
\hline 8. La peor señora del mundo (1992). Francisco Hinojosa. México & El trabajo en comunidad \\
\hline 9. Raúl pintado de azul (2001). Ana María Machado. Brasil & Los prejuicios culturales \\
\hline 10. La durmiente (2010). María Teresa Andruetto. Argentina & La igualdad de género \\
\hline 11. Federico y Federico (2013). Elena Dreser. México & La relación nieto y abuelo \\
\hline 12. Mi papá está enamorado (2014). Ruth Angulo. Costa Rica. & Las familias monoparentales \\
\hline 13. Maroma y la mariposa roja (2016). Ana María Machado. Brasil & El amor entre diferentes orígenes \\
\hline 14. El Desmemoriado (2016). Ruth Angulo. Costa Rica & La memoria y la desmemoria \\
\hline
\end{tabular}

Fuente: Elaboración propia

\section{Textos literarios}

1. Niña bonita

2. La durmiente

3. Federico y Federico

\section{Actividades}

1. Introducción a través de dinámicas y vídeos

2. Lectura de cuentos

3. Actividad grupal: Propuesta de actividad didáctica para aplicar a la realidad de aula 4. Presentaciones

\section{Materiales}

- Marcadores

- Lápices y crayolas de colores

- Papel construcción de colores

- Pegamento

- Masking tape

- Papelógrafos

- Hojas adicionales

- Copias de documentos

- Lapiceros

\section{Actividades a distancia}

Para el desarrollo de las actividades a distancia, en algunos casos, se utilizó el siguiente cuadro de presentación de la actividad.

\section{Cuadro 3. Descripción general de las actividades de tarea}

\begin{tabular}{|l|l|}
\hline Nombre de la actividad: & Objetivos específicos: \\
\hline Número de participantes: & Desarrollo de la actividad \\
\hline Rango de edades: & Materiales: \\
\hline Objetivo general: & Evaluación \\
\hline
\end{tabular}

Fuente: Elaboración propia

\section{Actividad 1}

Contenido: "La muñeca negra" (1889) de José Martí y corto animado del mismo nombre

Hacer una comparación entre los dos textos: el cuento y el vídeo. Semejanzas y diferencias.

Reflexionar y comparar las épocas con respecto a la producción, utilidad de los juguetes. 


\section{Actividad 2}

Contenido: "Nené traviesa" (1889) de José Martí

Comparar la época en que se escribió el cuento, finales del siglo XIX y el momento actual en relación con el entretenimiento, el acceso a la información, las imágenes visuales y los tipos de familia.

\section{Actividad 3}

Contenido: Maroma y la mariposa roja de Ana María Machado

El cuento plantea varios temas, entre ellos los siguientes:

a. El amor entre individuos de diferentes orígenes

b. La aceptación de personas diferentes

c. La capacidad de ver el mundo de diferentes maneras

Desarrollar una actividad siguiendo el esquema general del Cuadro 3.

\section{Actividad 4}

Contenido: Mi papá está enamorado de Ruth Angulo

El cuento enfoca el tema de las familias monoparentales_y algunas de las razones:

a. Soltería de la madre o el padre

b. Viudez

c. Padres divorciados o separados

Desarrollar una actividad siguiendo el esquema general del Cuadro 3.

\section{Actividad 5}

Contenido: La peor señora del mundo de Francisco de Hinojosa
Reflexionar, analizar y sistematizar argumentos a favor o en contra sobre su lectura.

\section{Actividad 6}

Contenido: Raúl pintado de azul de Ana María Machado

Escoger un capítulo y planear una actividad de lectura oral y colectiva en tres momentos: antes, durante y después.

Desarrollar una actividad siguiendo el esquema general del Cuadro 3 .

\section{Consideraciones finales}

De la experiencia pedagógica, en relación con la lectura de los textos literarios, fue provechosa en varios sentidos, por una parte, el diálogo entre el pasado y el presente en las obras de literatura infantil latinoamericana, suscitó análisis y discusión, de tal manera que se descubrieron puntos vinculantes a una temática general y particular, lo que permitió tener nociones fundamentales para la comprensión del panorama histórico y sociocultural del continente.

Por otro lado, el acercamiento al pensamiento martiano, permitió recordar algunos de sus principios pedagógicos, por ejemplo, el no subestimar la capacidad de lectura, comprensión y análisis de los niños y niñas. Este es un punto medular del pensamiento de José Martí, pues La Edad de Oro editada por el cubano en 1889 , pretendía deconstruir las nociones pedagógicas de la época, de la misma manera, García Monge hizo la recopilación y edición siguiendo este principio.

Además, los talles las personas participantes, lamentaron la poca información sobre 
la figura, obra, aporte pedagógico y editorial de Joaquín García Monge durante sus años de formación docente. La información y contenidos provocaron interés en las docentes, lo mismo que el pensamiento del cubano José Martí. Con base en lo anterior, y por tratarse de un proyecto de investigación de nuestra institución, organizó y diseñó un curso anual dirigido a los docente de primaria, titulado: "Cultura, educación y sociedad mediante la literatura infantil latinoamericana: de La Edad de Oro a la actualidad". El curso se impartió en el año 2018 entre los meses de abril y diciembre en la modalidad semipresencial.

Debido a la buena acogida de este curso, se amplió y propuso como optativo de la oferta del IDELA. Se considera fundamental que las futuras personas docentes que se incorporarán al sistema educativo nacional en el sector de educación primaria se hayan empapado del pensamiento pedagógico de estos grandes maestros, el cubano José Martí y el costarricense Joaquín García Monge. Dentro de la universidad, el curso pretende vincular al estudiante a la literatura infantil latinoamericana, mediante la lectura de textos presentes en La Edad de Oro editada por Joaquín García Monge, en combinación con textos clásicos y de Literatura Infantil y Juvenil contemporánea. Está dirigido a estudiantes del nivel de Bachillerato, de toda la comunidad estudiantil, con especial interés en las carreras de Enseñanza y sus énfasis.

En síntesis, de las primeras experiencias pedagógicas iniciadas en el 2017, nacieron otras propuestas como las descritas en los párrafos anteriores. Cabe destacar que de las personas participantes surgieron las necesidades y recomendaciones que alimentaron al proyecto de investigación en todas sus fases.

Se evidenció que hace falta en la formación de las personas docentes una visión con líneas enfáticas en América Latina. Es decir, una propuesta que toque el latinoamericanismo, entendido como una forma de pensamiento crítico que permite recuperar nuestro pasado para poder entender y analizar la realidad que se vive en nuestros países, y así lograr vencer el colonialismo mental que nos asecha.

Como visión prospectiva, es imperativo dar seguimiento a los procesos de acercamiento, reflexión y capacitación con docentes de primaria que laboran en el Ministerio de Educación Pública. Además, difundir y promocionar la recuperación de los textos de La Edad de Oro sistematizada y editada por el costarricense Joaquín García Monge, es una puerta que abre nuestra memoria.

\section{Referencias}

Alavez, A. (2014). Interculturalidad: concepto, alcances y derecho. Centro de Producción Editorial del GPPRD: México, D.F. https://rm.coe. int $/ 1680301 \mathrm{bc} 3$

Andricaín, S y Cerrillo, P (2018). Puentes de palabras: 25 autores iberoamericanos de narrativa para jóvenes. Ediciones de la Universidad de Castilla-La Mancha.

Andruetto, T. (2016). La lectura, otra revolución. Fondo de Cultura Económica: México, D.F. 
Aguado, T. (2003). Pedagogía Intercultural. Universidad Nacional de Educación a Distancia: Madrid.

Angulo, R. (2014). Mi papá está enamorado. Editorial Costa Rica: San José. . (2016). El desmemoriado. Editorial Costa Rica: San José.

Bornemann, E. (2015). Un elefante ocupa mucho espacio. Editorial Loqueleo: Buenos Aires.

Cerrillo, P y Sotomayor, V. (2016). Censuras y LIJ en el siglo XX (En España y 7 países latinoamericanos. Ediciones de la Universidad de Castilla-La Mancha: Cuenca.

Colomer, T. (2010). Introducción a la literatura infantil y juvenil actual. Editorial Síntesis: Madrid.

Dreser, E. (2013). Federico y Federico. Editorial Amaquemecan: México D. F.

Doumer, B. y Barnes, A. (2015). El pueblo que no quería ser gris. Editorail Colihue: Buenos Aires.

Ferrero, A. (1985). Las fuentes de la literatura infantil y el mundo mágico. Ministerio de Cultura Juventud y Deportes: San José.

Fuentes, C. (1992). El espejo enterrado. Fondo de Cultura Económica: México, D. F.

García Monge, J. (1921). La Edad de Oro de José Martí. San José: El Convivio de los Niños.

. Repertorio Americano. Semanario de Cultura Hispánica de Filosofía y Letras, Artes, Ciencias y Educación, Misceláneas y Documentos. Tomos del 8 al 20, años 1924-1930.
Guevara, A. y Molfino, M. (2005). La censura y la destrucción de los libros en el último gobierno de facto (1976-1983). Universidad de la Plata. En: http://www.memoria.fahce. unlp.edu.ar/trab_eventos/ev.6579/ ev.6579.pdf

Halbwachs, M. (1968). La mémoire collective. Paris, Puf.

López Tames, R. (1990). Introducción a la literatura infantil. Publicaciones de la Universidad de Murcia.

Machado, A. M. (2016). Maroma y la mariposa roja. Ediciones Castillo: México D.F.

Manguel, A. (1998). Una historia de la lectura. Editorial Alianza: Madrid.

Martí, J. (2005). La Edad de Oro. San José: Editorial de la Universidad Estatal a Distancia.

Ministerio de Educación Pública (2016). Marco teórico conceptual y normativo básico, para la aplicación de la Educación Intercultural en el Sistema Educativo Costarricense, de acuerdo con su carácter Multiétnico y Pluricultural. Colypro.

Montes, G. (1999). La frontera indómita. En torno a la construcción y defensa del espacio poético. Fondo de Cultura Económica: México, D.F.

Mora, C. (2016). Los derechos humanos. Multiculturalidad y ciudadanía en un mundo globalizado. Editorial de la Universidad de Costa Rica: San José.

Moreno, M. (1995). Aportes culturales y deculturación. Pablo de la Torriente, editorial: La Habana, 47 páginas, localizable en: http://catalogo. academiadominicanahistoria.org. 
do/cgi-bin/koha/opac-ISBDdetail . pl?biblionumber $=5647$

Polastron, L.X. (2007). Libros en llamas. Historia de la interminable destrucción de bibliotecas. Fondo de Cultura Económica: México D.F.

Skármeta, A. (2011). La Composición. Ediciones Ekaré: Barcelona.
Szurmuk, M. y Mckee, R. (2013). Diccionario de estudios culturales latinoamericanos. Editorial Siglo XXI: México,D.F.

Oliva, M. (2008). José Martí en la historia y la cultura costarricense. Heredia: Editorial de la Universidad Nacional de Costa Rica. 


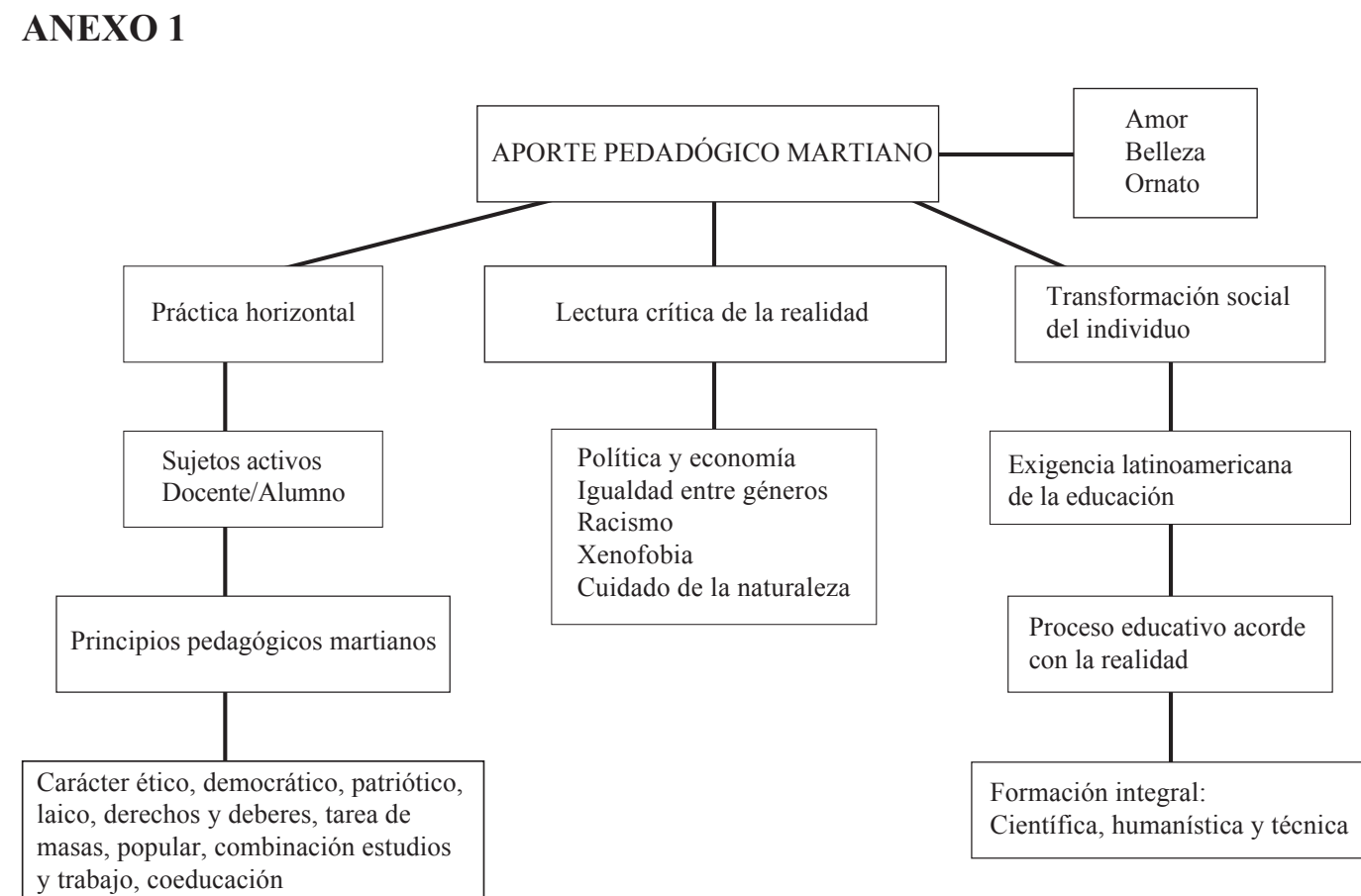

Fuente: Elaboración propia 